\title{
VULNERABILIDADE À CIRCULAÇÃO DO VÍRUS DA RAIVA POR MEIO DO CICLO SECUNDÁRIO NA ZONA RURAL DO MUNICÍPIO DE SÃO PEDRO - SP
}

\author{
(Vulnerable areas to the circulation of rabies virus through the secondary cycle in the \\ Municipality of São Pedro - SP)
}

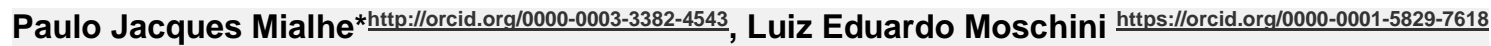

Universidade Federal de São Carlos, Departamento de Ciências Ambientais, São Carlos - SP Brasil.

*Contato para correspondência: paulomialhe@gmail.com

RESUMO - A raiva é uma enfermidade zoonótica, causada por um vírus do gênero Lyssavirus, que acomete o sistema nervoso central (SNC), sendo caracterizada como uma encefalomielite viral aguda de caráter progressivo, com letalidade próxima de $100 \%$.A presença de morcegos potencialmente infectados com o vírus da raiva em áreas antrópicas constitui uma fonte de contaminação para animais de estimação e seres humanos, fato que possibilita a transmissão do vírus da raiva do morcego infectado na ocasião da predação ou contato, podendo constituir um importante elo entre o ciclo aéreo e o terrestre da raiva chamado ciclo secundário. Este trabalho teve por objetivo detectar áreas vulneráveis à circulação do vírus rábico por meio do ciclo secundário na zona rural do município de São Pedro - SP, utilizando modelo de análise multicritério em Sistema de Informações Geográficas (SIG). Devido à ausência de casos de raiva na região, a vulnerabilidade à circulação do vírus da raiva no município de São Pedro variou em função da distância dos abrigos, do tamanho da população de morcegos que ocupavam os abrigos e do número de carnívoros domésticos em residências rurais onde havia colônias de morcegos habitando o forro. A modelagem em SIG dos fatores de vulnerabilidade a presença do vírus da raiva possibilita otimizar das ações educativas e de vigilância epidemiológica, concentrando seus esforços nas áreas mais vulneráveis, poupando assim tempo e recursos e aumentando a eficiência dos serviços.

Palavras-chave: SIG, raiva, morcego, zoonose, risco.

ABSTRACT - The presence of bats potentially infected with the rabies virus in anthropic areas constitutes a source of contamination for pets and humans, a fact that allows the transmission of the rabies virus from the infected bat at the time of predation or contact, and can constitute an important link between the air and terrestrial cycle of rabies called the secondary cycle. This work aimed to detect areas vulnerable to the circulation of the rabies virus through the secondary cycle in the rural area of the city of São Pedro - SP, using a multicriteria analysis model in Geographic Information System (GIS). Due to the absence of rabies cases in the region, the vulnerability to the circulation of the rabies virus in the municipality of São Pedro varied according to the distance from the shelters, the size of the bat population that occupied the shelters and the number of domestic carnivores in rural residences where there were bat colonies inhabiting the ceiling. The modeling in GIS of the vulnerability factors the presence of the rabies virus makes it possible to 
optimize the educational and epidemiological surveillance actions, focusing its efforts on the most vulnerable areas, thus saving time and resources and increasing the efficiency of services.

Palavras-chave - GIS, rabies, bats, zoonosis, risk.

\section{INTRODUÇÃo}

A raiva é uma enfermidade zoonótica, causada por um vírus RNA do gênero Lyssavirus, que acomete o sistema nervoso central, sendo caracterizada como uma encefalomielite viral aguda de caráter progressivo, com letalidade próxima de 100\%. Acomete diferentes espécies de mamíferos terrestres e aéreos, inclusive o homem, representando um sério problema de saúde pública em todo o mundo. Sua transmissão ocorre principalmente pelo contato com a saliva do hospedeiro contendo 0 agente etiológico em feridas ocasionadas por mordeduras ou arranhaduras de animais infectados, podendo também ser ocasionada por lambeduras na pele lesionada ou em mucosas, sendo estas formas menos comumente encontradas (Marinho, 2015; Pisa, 2015).

Na natureza, esse vírus é mantido por ciclos epidemiológicos ocasionalmente inter-relacionados, denominados ciclos urbano, silvestre, aéreo e rural. $\mathrm{O}$ ciclo urbano se refere à raiva em cães e gatos domésticos, sendo de grande importância em países do terceiro mundo. O ciclo silvestre envolve saguis, cachorros do mato e raposas, dentre outros animais silvestres terrestres. $\mathrm{O}$ ciclo aéreo refere-se à raiva em morcegos das mais diferentes espécies, sendo o maior responsável pela manutenção do vírus em uma determinada área. $\mathrm{O}$ ciclo rural refere-se à raiva dos herbívoros, envolvendo principalmente os bovinos e equinos, e cujo principal transmissor é o morcego hematófago Desmodus rotundus (Pisa, 2015; Moutinho et al., 2015).

D. rotundus utiliza diferentes tipos de abrigos: os diurnos, ou permanentes, onde se alojam a maior parte do tempo; os noturnos, onde permanecem o tempo necessário para a digestão após a alimentação para voltar ao abrigo permanente, sendo chamado de digestórios. (BRASIL, 2009).

A raiva vem passando por uma transição epidemiológica na qual o ciclo envolvendo quirópteros vem crescendo em importância. No Brasil, entre 2002 e 2009, dos casos de raiva em 1.163 amostras de morcegos, 80\% representavam morcegos não hematófagos e apenas $20 \%$ hematófagos. Morcegos com outras especialidades alimentares acabam sendo vias de transmissão do vírus da raiva, pois vivem em grandes colônias nos abrigos diurnos e disputam por território, nessa interação acabam transmitindo o vírus uns para os outros, além do fato de algumas espécies terem o habito de se lamberem, como o próprio $D$. rotundus, que utiliza esse ato para limpar uns aos outros (Leite, 2018).

No Brasil encontram-se 180 espécies agrupadas em 68 gêneros e 9 famílias: Phyllostomidae, Molossidade, Vespertilionidae, Emballorunidae e as famílias Noctilionidae, Mormooopidae, Natalidae, Furipteridae e Thyropteridae (Reis et al, 2017; Nogueira et al., 2014). Destas, 25 espécies já foram observadas explorando refúgios em habitações humanas (Sodré et al., 2010) e pelo menos 43 espécies foram afetadas pelo vírus da raiva, distribuídas em quatro famílias - Desmodontidae, Vespertilionidae, Molossidade e Emballonuridae (Sodré et al., 2010; Almeida, 2014; Batista et al., 2007).

Considerando que todas as espécies de morcegos são passíveis de adquirirem o vírus da raiva principalmente por meio da mordedura por morcego 
infectado, o conhecimento sobre as espécies que coabitam com as hematófagas também é importante. $D$. rotundus é uma das espécies que mais coabita com outras em diversos tipos de refúgios artificiais, dentre eles residências. Dados de espécies que coabitam em abrigos artificiais com $D$. rotundus nos estados do sudeste do Brasil incluem Anoura caudifer, Glossophaga soricina, Lonchorhina aurita, Lophostoma brasiliense, Trachops cirrhosus, Carollia perspicillata, Platyrrhinus lineatus, Histiotus velatus e Myotis riparius (Almeida, 2014).

A notificação dos casos de raiva em morcegos não hematófagos tem aumentado significativamente e o ciclo aéreo vem apresentando crescimento no país. O risco de transmissão do vírus pelo morcego é sempre elevado, independentemente de espécie e gravidade do ferimento, logo, toda agressão por morcego é considerada grave. As alterações ambientais que vêm ocorrendo nas áreas rurais vêm interferindo na distribuição espaço-temporal de diversas enfermidades zoonóticas (Moutinho et al. 2015).

A presença de morcegos potencialmente infectados com o vírus da raiva em áreas antrópicas representa um problema sério, especialmente para animais de estimação e seres humanos, constituindo-se em uma fonte de contaminação perigosa, particularmente pela possibilidade de passar como insuspeita (Batista et al. 2007).

A predação de morcegos por carnívoros domésticos (cães e gatos) constitui uma relação propicia para a transmissão do vírus da raiva. Os felinos são predadores naturais dos quirópteros, fato que possibilita a transmissão do vírus da raiva deste animal infectado na ocasião da predação ou contato, podendo constituir um importante elo entre o ciclo aéreo e o terrestre da raiva. Tal fato pode ocorrer caso haja o acesso aos refúgios de morcegos, situação em que o gato pode caçar diretamente nas saídas dos abrigos ou quando estão caídos no solo. Esses animais, uma vez infectados por variantes de raiva de quirópteros, podem transmitir a doença para o ser humano (Moraes et al., 2011).

No mundo, o primeiro registro deste ciclo, chamado secundário (quiróptero/felino/homem) ocorreu em área urbana do município de Dracena, interior do estado de São Paulo, em 2016. Uma mulher foi a óbito por raiva após ser agredida por sua gata raivosa, que havia anteriormente capturado um quiróptero infectado com o vírus da raiva (Moraes et al., 2011).

O serviço veterinário oficial é responsável por proteger a saúde pública e animal. Uma ferramenta que auxilia na busca desse objetivo é a análise de risco, que começou a ser utilizada na década de 1990 pelos serviços veterinários oficiais. Para a realização de uma análise de risco, inicialmente deve-se identificar o perigo, o qual na área da saúde animal, geralmente, é o agente patogênico causador de uma doença. A etapa subsequente é a avaliação de riscos, na qual devem ser ponderadas, com suporte de técnicas específicas, as formas de ocorrência do perigo, bem como a magnitude de suas consequências (Santos, 2016).

Entre as técnicas utilizadas na análise de risco, a análise de decisão por múltiplos critérios tem tido um crescente uso. Essa metodologia consegue associar e analisar, conjuntamente, diversas variáveis e, quando integrada a um Sistema de Informação Geográfica (SIG), incorpora a dimensão espacial, tornando a análise mais ampla. A análise de risco tornou-se um importante instrumento utilizado pelos gestores dos serviços veterinários oficiais na tomada de decisões, contribuindo para a escolha de alternativas que confiram, cientificamente, o menor risco sanitário (Santos, 2016). 
Entende-se por vulnerabilidade a inter-relação do conjunto de variáveis relacionadas à capacidade de ingresso do transmissor em determinada área e à circulação viral. Tais fatores possibilitam a difusão da doença para novas áreas e são facilitadores desse processo. A análise da vulnerabilidade do ambiente refere-se à capacidade de ingresso do transmissor numa área e a circulação viral. A recomendação da Instrução Normativa (IN) MAPA no 05/2002 que estabelece para a condução de medidas sanitárias (como o controle de morcegos hematófagos) em área de foco de raiva em herbívoros, a fixação de uma distância de $12 \mathrm{~km}$ a partir do foco para atuação, seja com base no modelo de círculos concêntricos ou de bloqueio linear (BRASIL, 2002; BRASIL, 2009).

Dentre as técnicas disponíveis para avaliação quantitativa de riscos, está a análise de decisão por múltiplos critérios. Utilizada para identificar as áreas de risco, é uma solução que permite integrar conjuntos distintos de variáveis expressas por valores e ponderações, conseguindo integrar e analisar, conjuntamente, diversos critérios ajudando os gestores na tomada de decisão. Amplamente utilizada para o mapeamento de susceptibilidade e de aptidão de terras para diversas finalidades, essa técnica tem sido aplicada de forma crescente na área da veterinária, em especial para a detecção de áreas vulneráveis para a ocorrência de enfermidades animais e, também para avaliar sistemas de vigilância animal (Arsevska et al., 2015; Brookes et al., 2014).

A análise de riscos utilizando-se SIGs, possibilita integrar informações referentes aos fatores de risco para o desenvolvimento de doenças permitindo o mapeamento de zonas de risco, o que pode contribuir na prevenção e controle, uma vez que permite delinear intervenções com o objetivo de reduzir as populações de vetores, controlar as populações de reservatório e implementar ações de vigilância.

Este trabalho teve por objetivo detectar áreas vulneráveis à circulação do vírus rábico por meio do ciclo secundário no município de São Pedro - SP, utilizando modelo de análise multicritério em Sistema de Informações Geográficas (SIG).

\section{MATERIAL E METODOS}

O presente estudo foi realizado na área do Município de São Pedro - SP, região serrana localizada na cuesta basáltica do estado de São Paulo, a $190 \mathrm{~km}$ a noroeste da capital do estado, com uma área $609,091 \mathrm{~km}^{2}$. Apresenta altitudes que variam entre as cotas 500 e 900 metros e tem como vizinhos os Municípios de Santa Maria da Serra, Torrinha, Brotas, Itirapina, Ipeúna, Charqueada e Piracicaba. O local oferece boas condições para a formação de abrigos de morcegos, tais como casas, grutas, viadutos, túneis e temperatura favoráveis, assim como recursos (água e alimento em abundância).

Foram realizadas buscas por colônias de morcegos hematófagos habitando abrigos naturais e artificiais e de abrigos de morcegos não hematófagos habitando residências por toda zona rural no município de São Pedro-SP, entre dezembro de 2001 a setembro de 2002. Todas as propriedades rurais foram vistoriadas quanto a presença de morcegos habitando abrigos naturais e artificiais, incluindo residências. Os abrigos localizados foram georreferenciados com o uso de receptor GPS ${ }^{1}$ de navegação $\operatorname{Garmin}^{\circledR}$, as espécies de morcegos foram identificadas através da observação visual e sua população estimada.

${ }^{1}$ Global Positioning System 
A estimativa populacional nas colônias foi realizada calculando-se o número de morcegos existentes em um metro quadrado e multiplicando a seguir pela área total ocupada pelos mesmos, além de evidencias indiretas, como o volume de fezes existentes no chão, paredes ou outras estruturas. Fezes de $D$. rotundus, são caracteristicamente negras em pequenas gotas (quando há poucos indivíduos no local) ou então manchas escorridas e poças de fezes (quando há muitos individuos). Pode-se diferenciar se esse é um abrigo ativo, ou seja, se naquele momento há a presença de morcegos hematófagos; ou inativo, se já houve essa presença (Oliveira et al.,2009).

Foram também coletados dados na Vigilância Epidemiológica Municipal e Casa da Agricultura de São Pedro referentes a casos de raiva em morcegos, pessoas e animais domésticos no município de São Pedro durante o período em estudo.

A partir desses dados, foi elaborado um plano de informação em SIG utilizando-se o software ArcGis $10^{\circledR}$ e construído um mapa de vulnerabilidade à circulação do vírus da raiva entre morcegos hematófagos por meio do ciclo aéreo, que por sua vez poderiam ser fontes de infecção para carnívoros domésticos e pessoas que coabitam com esses animais (ciclo secundário).

Em geoprocessamento, a análise multicritério pode ser entendida como um conjunto de procedimentos com o objetivo de reunir diversos planos de informação espaciais juntamente com as suas variações internas, ou classes de legenda, que depois de atribuídos pesos e notas, irá gerar uma nova informação. Em outras palavras, a análise multicritérios permite a junção de vários mapas, aos quais são atribuídos ordem de importância entre eles e o grau de impacto de cada classe de legenda para o objetivo final do estudo, com o pressuposto que o cenário final será originado do cruzamento de todas as informações inseridas. Portanto a técnica em primeiro momento gera o diagnóstico espacial vigente e posteriormente gera mapas prognósticos (Moura, 2007).

Munier (2011) destaca cinco dentre os métodos de análise multicritério mais populares: MAUT, ELECTRE, PROMETHEE, TOPSIS e AHP, expondo que não tem sentido definir métodos superiores a outros, porém são apresentados limites e potencialidades, fornecendo a possibilidade da escolha do método mais adequado para o modelo.

Para o presente trabalho foi utilizado o método AHP - Analytic Hierarchy Process (Saaty,1992), bastante difundido na literatura específica de SIG, e que também pode ser aplicado baseado no comportamento dos dados. Este método consiste em uma estrutura hierárquica montada para auxiliar a tomada de decisões tendo como base o desenvolvimento de comparações pareadas dos valores de entrada, seguido pela a análise de consistência da solução definindo a hierarquia de participação de cada variável, o que possibilita estruturar o modelo de pesos e notas em números ordinais, que podem ser transpostos nos pixels correspondentes de cada variável inserida, considerando que estas sejam representadas como dados matriciais (Munier, 2011; Sadasivuni,2009).

Uma das formas de avaliar o comportamento dos dados baseia-se no cruzamento da superfície potencial de ocorrência do fenômeno com as variáveis utilizadas por meio da leitura dos pixels correspondentes. Ao final da avaliação, é gerada uma nova superfície, sintetizada pela média ponderada de cada variável por meio de álgebra de mapas. Os resultados consistem em áreas em escala ordinal, que podem ser classificadas em escalas de intervalo ou nominal, e podem representar prioridades, conflitos, riscos entre outros, com base nas variáveis 
escolhidas (Pinto, 2015). Para a construção da superfície potencial, utilizou-se o interpolador Kernel e Cartas Geográficas na escala 1:50.000 do IBGE.

Para a construção de mapas de vulnerabilidade, foram analisadas as variáveis "Distancia Euclidiana dos abrigos de morcegos", "População de morcegos existentes nos abrigos", "Número de carnívoros domésticos presentes nas residências" e "Casos de raiva em pessoas, animais ou morcegos".

Em relação à distância dos abrigos de morcegos, foram construídos em SIG círculos concêntricos com diferentes raios de distância entre si a partir de cada abrigo até a distância de $12 \mathrm{~km}$, baseado em recomendação do MAPA que estabelece para a condução de medidas sanitárias a fixação de uma distância de 12 km a partir do foco de raiva em herbívoros e para a condução de medidas sanitárias, incluindo o controle de morcegos hematófagos.

Baseado nas distâncias médias de vôo de $D$. rotundus a partir dos abrigos na região (Mialhe e Moschini, 2018) foram atribuídos pesos maiores para distâncias dentro de raios mais próximos do abrigos, decrescendo à medida que esta distância aumentava, conforme a Tabela 1.

Tabela 1. Pesos atribuídos a Distância dos abrigos de morcegos e seu grau de vulnerabilidade a circulação do vírus da raiva.

\begin{tabular}{ccc}
\hline Distâncias dos abrigos & Peso & Grau de Vulnerabilidade \\
\hline De 0 a $1 \mathrm{~km}$ & 5 & Muito alta \\
De 1,1 a $3 \mathrm{~km}$ & 4 & Alta \\
De 3,1 a $5 \mathrm{~km}$ & 3 & Média \\
De 5,1 a $9 \mathrm{~km}$ & 2 & Baixa \\
De 9,1 a $12 \mathrm{~km}$ & 1 & Muito baixa \\
\hline
\end{tabular}

Em relação a variável "População de morcegos encontrados nos abrigos", foram atribuídos valores crescentes à vulnerabilidade da circulação do vírus da raiva à medida que essa população aumentava, conforme a Tabela 2.

Tabela 2 - Pesos atribuídos quanto ao número de morcegos existentes nos abrigos e respectivos graus de vulnerabilidade a circulação do vírus da raiva.

\begin{tabular}{ccc}
\hline $\begin{array}{c}\text { Número de morcegos existentes nos } \\
\text { abrigos }\end{array}$ & Peso & Vulnerabilidade \\
\hline Entre 1 e 4 morcegos & 1 & Muito baixa \\
Entre $5-14$ morcegos & 2 & Baixa \\
Entre $15-49$ morcegos & 3 & Média \\
Entre $50-99$ morcegos & 4 & Alta \\
Acima de 100 morcegos & 5 & Muito alta \\
\hline
\end{tabular}

Em relação a variável "População de carnívoros domésticos encontrados nas residências", foram atribuídos valores crescentes à vulnerabilidade da circulação do vírus da raiva à medida que essa população aumentava, conforme mostra a Tabela 3. 
Tabela 3 - Pesos atribuídos quanto ao número de carnívoros domésticos existentes nas residências e respectivos graus de vulnerabilidade a circulação do vírus da raiva.

\begin{tabular}{ccc}
\hline $\begin{array}{c}\text { Número de carnívoros domésticos } \\
\text { nas residências }\end{array}$ & Peso & Grau de Vulnerabilidade \\
\hline Acima de 5 & 5 & Muito alta \\
4 a 5 & 4 & Alta \\
3 a 4 & 3 & Média \\
1 a 2 & 2 & Baixa \\
0 & 1 & Muito baixa \\
\hline
\end{tabular}

Em relação a variável "Número de casos de raiva", foi considerado o número de casos de raiva em animais domésticos, morcegos e pessoas nos focos de raiva e atribuídos valores crescentes de vulnerabilidade da circulação do vírus rábico conforme esses números de casos aumentam, dentro de um raio de distância fixa de $12 \mathrm{~km}$ a partir dos abrigos. Esses pesos e graus de vulnerabilidade estão expressos na Tabela 4.

Tabela 4. Pesos atribuídos a partir do número de casos de raiva em animais e pessoas e seu grau de vulnerabilidade a circulação do vírus da raiva.

\begin{tabular}{ccc}
$\begin{array}{c}\text { Número de casos de raiva em animais e } \\
\text { pessoas }\end{array}$ & Peso & $\begin{array}{c}\text { Grau de } \\
\text { Vulnerabilidade }\end{array}$ \\
\hline Nenhum & 1 & Baixa \\
1 & 2 & Médio \\
Entre 2 e 5 & 4 & Alta \\
Acima de 5 & 5 & Muito alta \\
\hline
\end{tabular}

Os dados obtidos foram combinados com essas variáveis e pesos com base na metodologia proposta por Saaty (1980), com o propósito de garantir a consistência em todas as ponderações realizadas. Portanto foram elaboradas matrizes para cada mapa elaborado, permitindo a realização de operações matemáticas no Software ArcGis $10^{\circledR}$.

O método matemático utilizado para sobreposição foi o de soma ponderada, utilizando a ferramenta de álgebra de mapa (Single output Map Algebra), sendo obtido a partir desta o mapa de vulnerabilidade à circulação do vírus rábico por meio do ciclo secundário no município de São Pedro - SP agrupado em cinco classes (Muito Baixa, Baixa, Média Alta e Muito Alta), utilizando o método de classificação Natural Breaks.

\section{RESULTADOS}

Foram encontrados 320 D. rotundus distribuídos em oito abrigos não habitados por pessoas e 47 morcegos não hematófagos habitando o forro de 12 residências humanas. $67 \%$ dos abrigos de $D$. rotundus encontrados eram artificiais, a maioria casas abandonadas e ocupados por $D$. rotundus machos. Somente em um abrigo ( $\mathrm{H} 6$ - $\mathrm{NH} 1$ ) foram encontrados $D$. rotundus compartilhando abrigo com outros 12 morcegos não hematófagos, do gênero Glossophaga spp.

Os morcegos não hematófagos encontrados pertenciam aos gêneros Molossus spp., Glossophaga spp., Carollia spp. e Myotis spp. Em todas as residências em que foram encontradas espécies de morcegos não hematófagos, havia frestas no telhado que permitia a entrada e saída de morcegos que ali 
habitavam o forro. As pessoas que ali residiam possuíam de dois a oito carnívoros domésticos (cães e/ ou gatos) que estavam vacinados contra a raiva, com exceção de um gato que habitava a residência $\mathrm{NH} 7$ e um cão que habitava a residência NH6.

A localização geográfica e população encontrada nos abrigos de morcegos e o número de carnívoros domésticos habitando residências estão relacionadas na Tabela 5.

Tabela 5. Localização geográfica dos abrigos de $D$. rotundus, abrigos de morcegos não hematófagos, residências com carnívoros domésticos e população estimada.

\begin{tabular}{|c|c|c|c|c|c|}
\hline $\begin{array}{l}\text { Abrigos } \\
\text { de } \\
\text { morcegos }\end{array}$ & UTM East & $\begin{array}{l}\text { UTM } \\
\text { North }\end{array}$ & $\begin{array}{c}\text { População } \\
\text { estimada } \\
\text { de } \\
\text { D.rotundus }\end{array}$ & $\begin{array}{c}\text { População } \\
\text { estimada de } \\
\text { morcegos } \\
\text { não } \\
\text { hematófagos }\end{array}$ & $\begin{array}{c}\text { População } \\
\text { de } \\
\text { carnívoros } \\
\text { domésticos }\end{array}$ \\
\hline $\mathrm{H} 1$ & 7500675 & 804525 & 200 & & 0 \\
\hline $\mathrm{H} 2$ & 7505637 & 807930 & 2 & & 0 \\
\hline $\mathrm{H} 3$ & 7504165 & 196477 & 1 & & 0 \\
\hline $\mathrm{H} 4$ & 7506686 & 193978 & 1 & & 0 \\
\hline H5 & 7508350 & 198959 & 11 & & 0 \\
\hline $\mathrm{H} 6-\mathrm{NH} 1$ & 7507369 & 198440 & 100 & 12 & 0 \\
\hline $\mathrm{H} 7$ & 7508612 & 807873 & 4 & & 0 \\
\hline $\mathrm{H} 8$ & 7498267 & 195475 & 1 & & 0 \\
\hline $\mathrm{NH} 2$ & 7499394 & 197801 & & 7 & 5 \\
\hline $\mathrm{NH} 3$ & 7498243 & 207330 & & 6 & 4 \\
\hline $\mathrm{NH} 4$ & 7509410 & 200460 & & 5 & 6 \\
\hline NH5 & 7509309 & 202768 & & 8 & 2 \\
\hline $\mathrm{NH} 6$ & 7497658 & 199764 & & 14 & 8 \\
\hline $\mathrm{NH} 7$ & 7498261 & 198519 & & 20 & 4 \\
\hline NH8 & 7505925 & 201707 & & 8 & 3 \\
\hline $\mathrm{NH} 9$ & 7512823 & 200090 & & 7 & 6 \\
\hline $\mathrm{NH} 10$ & 7496448 & 199191 & & 6 & 8 \\
\hline $\mathrm{NH} 11$ & 7493405 & 196018 & & 18 & 3 \\
\hline $\mathrm{NH} 12$ & 7498072 & 192466 & & 4 & 3 \\
\hline Total & & & 367 & 47 & 51 \\
\hline
\end{tabular}

Legenda: $\mathrm{H}$ : abrigo de morcego hematófago, $\mathrm{NH}$ : abrigos com morcegos não hematófagos.

A fim de verificar a existência do vírus da raiva na população de morcegos, a Coordenadoria de Defesa Agropecuária enviou amostras de morcegos hematófagos (doze $D$. rotundus, $3,75 \%$ do total) e não hematófagos (quatro morcegos, $7,27 \%$ do total) ao Instituto Pasteur para realização de exames de imunofluorescência direta (pesquisa do antígeno rábico) e prova biológica. Os resultados obtidos para todos os morcegos analisados (hematófagos e não hematófagos) foram negativos para o vírus da raiva.

Os dados foram submetidos à análise de decisão por múltiplos critérios em SIG resultando no mapa de vulnerabilidade à circulação do vírus da raiva no município de São Pedro - SP, conforme mostrado na Figura 1.

Os locais que apresentaram vulnerabilidade média para a circulação do vírus da raiva por meio do ciclo secundário foram no entorno dos abrigos $\mathrm{H} 2, \mathrm{H} 3, \mathrm{H} 4, \mathrm{H} 7$, 
e H8, todos abrigando poucos (de um a quatro) morcegos hematófagos e nenhum morcego não hematófago ou carnívoro doméstico.

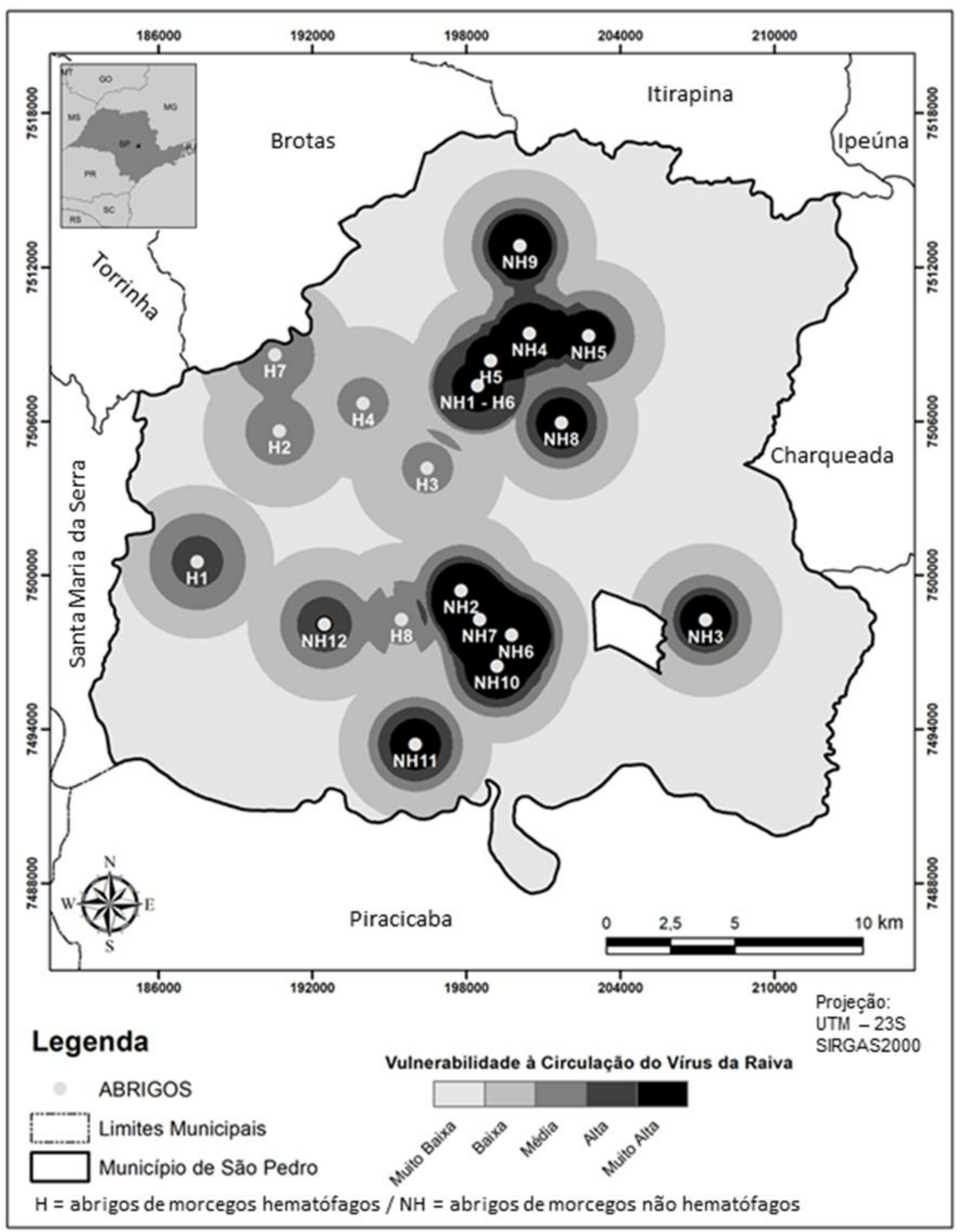

Figura 1. Mapa de Vulnerabilidade à circulação do vírus da raiva no Município de São Pedro- SP.

Os locais que apresentaram vulnerabilidade alta a circulação do vírus da raiva por meio do ciclo secundário foram no entorno dos abrigos $\mathrm{H} 1$ e NH12. $\mathrm{O}$ abrigo de morcegos hematófagos $\mathrm{H} 1$, apesar de abrigar uma elevada população de $D$. 
rotundus (100 morcegos), estava distante dos demais abrigos de morcegos e não havia nenhum carnívoro doméstico coabitando neste abrigo.

$\mathrm{O}$ abrigo de morcego não hematófago $\mathrm{NH} 12$, uma residência que abrigava apenas quatro morcegos não hematófagos, era habitada por três carnívoros domésticos, o que elevou a vulnerabilidade na área ao entorno deste abrigo.

As áreas com vulnerabilidade muito alta a circulação do vírus da raiva por meio do ciclo secundário foram aquelas aos arredores dos abrigos onde havia maior número de carnívoros domésticos associados a presença de morcegos, o que ocorreu no entorno de todos os abrigos de morcegos não hematófagos, assim como do abrigo $\mathrm{H} 5$ e do abrigo $\mathrm{H} 6-\mathrm{NH} 1$ no qual compartilhavam Glossophaga spp. e $D$. rotundus.

O abrigo H5 - uma gruta natural - apesar de não haver nenhum carnívoro doméstico habitando-o, possuía uma população de $D$. rotundus considerada de media vulnerabilidade, porem devido à proximidade do abrigo $\mathrm{H} 6-\mathrm{NH} 1$ que apresentava elevada população de $D$. rotundus e do abrigo $\mathrm{NH} 4$, foi classificado pelo modelo como possuindo vulnerabilidade muito alta.

\section{DISCUSSÃO}

No modelo utilizado, a variável "Número de morcegos existentes nos abrigos" é relevante porque a densidade populacional da colônia implica na disputa por alimento, fêmeas e hierarquia. Tal comportamento resulta em possíveis agressões e aumento do contato físico entre morcegos, aumentando dessa forma a possibilidade de transmissão do vírus da raiva entre os indivíduos que coabitam um abrigo.

Apesar de nenhum morcego neste estudo enviado ao Instituto Pasteur ter sido diagnosticado como positivo para o vírus da raiva, há registros de ocorrência de raiva em todos os gêneros de morcegos não hematófagos encontrados neste estudo (Kotait et al., 2007; Albas et al., 2009; Favaro, 2018). Estudo tipificação antigênica do vírus da raiva isolados em animais e humanos no Brasil detectaram a variante mais comum isolada entre as espécies de morcegos insetívoros foi a variante $3(D$. rotundus) (Favoretto et al., 2002) indicando que o morcego não hematófago está sendo contaminando com a variante mantida por populações de morcegos hematófagos (Campos, 2011).

Análise de amostras positivas para raiva provenientes de espécies de morcegos não hematófagos na região de Presidente Prudente - SP também demonstraram que a maioria das amostras pertencia a variante 3 (compatível com amostras isoladas de morcegos $D$. rotundus) tinha hábito alimentar insetívora, como Molosus rufus, e não apresentaram sinais clínicos de raiva. Os morcegos foram encontrados em área externa e interna de residências, em $8,8 \%$ dos casos houve algum tipo de exposição direta (agressão) dos morcegos infectados a pessoas e em 24,6\% a animais domésticos (Albas et al., 2009; Albas et al. 2011).

Com exceção do gênero Carollia spp., todos morcegos não hematófagos encontrados no município de S. Pedro compartilhavam abrigo outra espécie de morcego. Este gênero alimenta-se de frutos, néctar e insetos e apresenta ampla distribuição no Brasil, utilizando abrigos tanto em áreas florestais como urbanas (Reis et al., 2017). Há relatos de compartilhamento de Carollia perspicillata com D. rotundus e com o morcego nectarivoro Glossophaga soricina (Almeida, 2014). No município de São Pedro este foi o único gênero de morcego não hematófago que estava compartilhando abrigo com $D$. rotundus, em uma caverna (abrigo $\mathrm{H} 6$ - $\mathrm{NH} 1$ ). 
Os morcegos insetívoros do gênero Myotis spp. apresentam ampla distribuição geográfica entre os morcegos, e provavelmente dentre os mamíferos terrestres, excetuando-se o homem (Nowac, 1999). Há registros de Myotis riparius coabitando abrigos com D. rotundus, Glossophaga soricina e Carollia perspicillata; Myotis nigricans foram encontrados coabitando abrigos com Molossus molossus e Molossus rufus (Almeida, 2014). No município de S. Pedro, esse gênero foi encontrado compartilhando forros de residências com morcegos insetívoros do gênero Molossus spp.

Apesar da presença de abrigos de $D$. rotundus próximos a habitações rurais, é pouco provável que estes morcegos ataquem as pessoas, pois estes morcegos forrageiam preferencialmente herbívoros domésticos existentes nas proximidades dos abrigos (Mialhe, 2014), com maior importância relacionada ao ciclo rural da raiva.

Dessa forma, as pessoas apresentam uma maior susceptibilidade ao risco de infectarem-se com o vírus da raiva por meio da manipulação direta de morcegos infectados. Morcegos infectados com o vírus da raiva apresentam comportamentos erráticos, podendo adentrar nas residências e as pessoas podem sofrer agressões, principalmente crianças, devido à manipulação indevida.

A reintrodução da raiva em populações caninas ou felinas a partir do ciclo silvestre brasileiro é uma preocupação. Entre 2002 e 2012 os morcegos não hematófagos representaram a maior proporção de notificações no sudeste do país, sendo que o estado de São Paulo apresentou maior frequência de registros (Manrique-Rocha, 2014).

O município de Campinas registrou seu último caso de raiva humana em 1981. No ano seguinte, há o último registro de raiva em cão causado pela variante viral conhecida como "variante canina" ou "variante 2". Desde então, todos os casos de raiva registrados no município foram causados por variantes virais provenientes de morcegos. No município, a raiva tem se manifestado por intermédio do chamado ciclo aéreo, no qual os morcegos, hematófagos ou não hematófagos, mantém a circulação do vírus. A população felina, devido às baixas coberturas vacinais registradas nesta espécie e ao seu instinto de predação, é mais vulnerável a se infectar pelo vírus da raiva por contato com morcegos (Campinas, 2016).

No Brasil, até o ano de 2003, o ciclo epidemiológico de transmissão responsável pelos casos de raiva humana foi o relacionado à cães e gatos, com $72,5 \%$ dos casos. A ocorrência de dois surtos de raiva humana transmitido por morcegos, ocorridos nos municípios de Portel- Pará (15 casos) e Viseu-Pará (6 casos) em 2004 somado à diminuição da raiva em cães, inverteu o panorama epidemiológico da raiva e o morcego tornou-se o principal responsável pelos casos de raiva humana. Essa situação manteve-se no ano de 2005, devido os surtos por morcegos hematófagos no Pará e Maranhão, tendo sido notificado 29 casos transmitidos por morcegos, um por cão e um por primata (da Rosa et al., 2006; Brasil, 2005). Em outubro de 2005 foi notificado um novo foco de raiva humana transmitida por morcego hematófago no Maranhão (Brasil, 2005)

Tais incidentes geram preocupação dos profissionais envolvidos em ações de controle da raiva devido à possibilidade da reintrodução da raiva urbana em populações de carnívoros domésticos a partir de vírus associado a outros ciclos da infecção. O sucesso adaptativo do vírus rábico é atribuído à possibilidade de uma variante espécie-específica passar a infectar outras espécies e persistir ao longo do tempo e do espaço, chamado "spillover", que mantém os dois principais ciclos de 
transmissão: o urbano, tendo os carnívoros domésticos como principal reservatório, e o ciclo silvestre, com diferentes espécies de animais selvagens atuando como reservatórios ou transmissores, com importantes variações regionais (ManriqueRocha, 2014).

Alguns pesquisadores observaram que a raiva em morcegos não hematófagos precede a raiva bovina e em animais de estimação, sugerindo que os morcegos não hematófagos podem ser o elo entre a raiva silvestre e a raiva urbana e o fato de se detectar a variante mantida por morcegos hematófagos $D$. rotundus em cães e gatos mostra que o papel deste morcego no ciclo da raiva não está limitado à raiva silvestre (Campos, 2011).

A ausência de registros de casos de raiva no município não descarta a possibilidade de haver quirópteros infectados com raiva na região, sendo necessária a atualização dos dados periodicamente.

\section{CONCLUSÃO}

O monitoramento da presença do vírus da raiva em morcegos hematófagos e não hematófagos torna-se uma questão emergente para os serviços de saúde pública e animal. Nas populações rurais ou periurbanas que vivem próximas aos abrigos de morcegos hematófagos, como no município de São Pedro - SP, o problema se agrava, representando um desafio aos serviços de Vigilância Epidemiológica.

O modelo de áreas vulneráveis à circulação do vírus da raiva por meio do ciclo secundário no município de São Pedro - SP permite identificar as áreas com maior vulnerabilidade de ocorrência da raiva, e assim priorizar ações dos órgãos de saúde pública e animal.

\section{REFERENCIAS}

ALBAS, A.; SOUZA, E.A.N.; PICOLO, M.R.; FAVORETTO, S.R.; GAMA, A.R.; SODRE, M.M. Os morcegos e a raiva na região oeste do Estado de São Paulo. Revista da Sociedade Brasileira de Medicina Tropical, v.44, n.2, p. 201-205, 2011. Disponível em: https://www.scielo.br/scielo.php?pid=S003786822011005000001\&script=sci_abstract\&tIng=pt Acesso em 14/10/2019.

ALBAS, A; SOUZA E.A.N.; LOURENÇO R.A.; FAVORETTO S.R.; SODRÉ M.M. Perfil antigênico do vírus da raiva isolado de diferentes espécies de morcegos não hematófagos da Região de Presidente Prudente, Estado de São Paulo. Revista da Sociedade Brasileira de Medicina Tropical, v.42, n.1, p.15-17. 2009 [DOI:10.1590/S0037-86822009000100004]. Acesso em 14/10/2019.

ALMEIDA T.C.B. Morcegos (Mammalia, Chiroptera) em Refúgios Diurnos Artificiais na Região Sudeste do Brasil. 2014. Dissertação (Mestrado em Biologia Animal), Universidade Federal Rural do Rio de Janeiro. Disponível em: <http://www.ufrrj.br/posgrad/cpgba/teses/DISSERTACAO\%20THEANY_final.pdf>. Acesso em 14/10/2019.

ARSEVSKA, E.; HELLAL, J.; MEJRI, S.; HAMMAMI, S.; MARIANNEAU, P.; CALAVA, S. D.; HÉNAUX, V. Identifying areas suitable for the occurrence of Rift 
Valley Fever in North Africa: implications for surveillance. Transboundary and Emerging Diseases, 2015. [DOI:10.1111/tbed.12331] Acesso em 14/10/2019.

BATISTA, H.B.C.R.B.; FRANCO, A.C.F.; ROEHE, P.M. Raiva, uma breve revisão. Acta Scientiae Veterinariae, v.35, n.2.p.125-144, 2007. Disponível em: <http://www.lume.ufrgs.br/handle/10183/20621> Acesso em 14/10/2019.

BRASIL, Ministério da Agricultura, Pecuária e Abastecimento (MAPA). Controle da raiva dos Herbívoros: manual técnico. Brasília: Mapa/ACS, 2009. Disponível em: $<$ http://www.adepara.pa.gov.br/sites/default/files/manual\%20tecnico\%20para\%20con trole\%20da\%20raiva\%20dos\%20herb\%C3\%ADvoros.pdf>. Acesso em 14/10/2019.

BRASIL, Ministério da Saúde. Nota informativa: Informações sobre caso de raiva canina por variante 3 de quiróptero. 2016 Disponível em: <http://www.saude.gov.br/saude-de-a-z/crianca/961-saude-de-a-a-z/raiva/23634nota-informativa-informacoes-sobre-caso-de-raiva-canina-por-variante-3-dequiroptero>. Acesso em 14/10/2019.

BRASIL. Ministério da Agricultura, Pecuária e Abastecimento - MAPA, Programa Nacional de Controle da Raiva dos Herbívoros - PNCRH Instrução Normativa $\mathbf{n}^{\circ} \mathbf{5}$, de 01 mar. 2002. Aprova as normas técnicas para o controle da raiva dos herbívoros domésticos. Disponível em:

BRASIL. Ministério da Saúde. Secretaria de Vigilância em Saúde. Guia de Vigilância Epidemiológica. Série A. 7a. ed. Normas e Manuais Técnicos. Brasília: Ministério da Saúde; $2005 . \quad 816$ p. Disponível em: <http://bvsms.saude.gov.br/bvs/publicacoes/guia_vigilancia_epidemiologica_7ed.pd> Acesso em 14/10/2019.

BROOKES,V.J.;HERNÁNDEZ-JOVERB彑,M.; COWLEDC B.; HOLYOAKED, P.K., Ward MP Building a picture: Prioritisation of exotic diseases for the pig industry in Australia using multi-criteria decision analysis. Preventive Veterinary Medicine, v. 113, n. 1, p. 103-117, 2014. [DOI: 10.1016/j.prevetmed.2013.10.014] Acesso em 14/10/2019.

CAMPINAS, Secretaria Municipal de Saúde. Departamento de Vigilância em Saúde - DEVISA. Informe Técnico: Ocorrência de Raiva Felina em Campinas 12/2016. Disponível em: <http://www.saude.campinas.sp.gov.br/saude/vigilancia/informes/2016/Informe\%20T ecnico_Raiva_em_Felino_19_12_2016.pdf>. Acesso em 14/10/2019.

CAMPOS, A.C.A. Estudo genético da variante do vírus da raiva mantida por populações do morcego hematófago Desmodus rotundus 2011 Tese (Doutorado em Biotecnologia), Universidade de São Paulo/Instituto Butantã/Instituto de Pesquisas Tecnológicas. Disponível em: https://www.teses.usp.br/teses/disponiveis/87/87131/tde-14092011-175622/pt-br.php Acesso em 14/10/2019.

DA ROSA, E.S.T.; KOTAIT I.; BARBOSA, T.F.S.; CARRIERI, M.L.; BRANDÃO, P.E.; PINHEIRO A.S.; BEGOT, A.L., WADA, M. Y; DE OLIVEIRA, R.C.; GRISARD E.C.; 
FERREIRA, M.; LIMA, R.J.S.; MONTEBELLO, L.; MEDEIROS, D.B.A.; SOUSA, R.C.M.; BENSABATH, G.; CARMO, E.H.; VASCONCELOS P.F.C. Bat-transmitted Human Rabies Outbreaks, Brazilian Amazon. Emerging Infectious Diseases, v.12, n.8, p. 1197-202, 2006. Disponível em: https://www.scielo.br/scielo.php?pid=S003489102009005000073\&script=sci_arttext Acesso em 14/10/2019.

FAVARO, A.B.B.B.C. Positividade para o vírus da raiva em morcegos no estado de São Paulo e potenciais fatores de risco. 2018 Dissertação (Mestrado em Ciência Animal), Faculdade de Medicina Veterinária Campus de Araçatuba, Universidade Estadual Paulista. Disponível em: https://repositorio.unesp.br/handle/11449/166175 Acesso em 14/10/2019.

FAVORETTO, S.R.; CARRIERI, M.L.; CUNHA, S.E.M.; AGUIAR, E.A.C., SILVA L.H.Q.; SODRÉ M.M.; SOUZA, A.M.; KOTAIT, I. Antigenic typing of Brazilian rabies virus samples isolated from animals and humans, 1989-2000. Revista do Instituto de Medicina Tropical de São Paulo, São Paulo. v.44, n.2, p .91-5, 2002. Disponível em https://www.scielo.br/scielo.php?script=sci_arttext\&pid=S003646652002000200007 Acesso em 14/10/2019.

KOTAIT I.; CARRIERI M.C.; JÚNIOR P.C.; CASTILHO J.G.; OLIVEIRA R.N.; MACEDO C.I.; FERREIRA K.C.S.F.; ACHKAR S.M. Reservatórios silvestres do vírus da raiva: um desafio para a saúde pública BEPA, Boletim Epidemiológico Paulista, v.4 n.40,2007. Disponível em: http://periodicos.ses.sp.bvs.br/pdf/bepa/v4n40/v4n40a01.pdf. Acesso em 14/10/2019.

KOTAIT, I; TAKAOKA N.Y.; CARRIERI M.L. Manual Técnico Instituto Pasteur. Raiva - Aspectos gerais e clínica. São Paulo: Instituto Pasteur, 2009. Disponível em:

<http://www.saude.sp.gov.br/resources/institutopasteur/pdf/manuais/manual_08.pdf> . Acesso em 14/10/2019.

LEITE, A.C.C.P.; DOS ANJOS, D. M.; SIMÕES, E. M.; ALVES, J. R. A. A.; GOMES, A.A.B.; CLEMENTINO, I. J. ; AZEVEDO, S. S.; ALVES, C. J. Spatial characterization and identification of Chiroptera shelters and their relation to cases of rabies in production animals in semi-arid, Brazil, from 2007 to 2015 Semina: Ciências Agrárias, v.39, n.6, 2018. Disponível em: <http://www.uel.br/seer/index.php/semagrarias/article/view/32899/24603>. Acesso em 14/10/2019.

MANRIQUE-ROCHA, S. Raiva silvestre: o perfil epidemiológico no Brasil (2002 a 2012). 2014. Brasília. Dissertação (Mestrado em Saúde Animal), Faculdade de Agronomia e Veterinária, Universidade de Brasília. Disponível em: <http://repositorio.unb.br/bitstream/10482/18365/3/2014_SileneManriqueRocha.pdf>. Acesso em 14/10/2019.

MARINHO K.M. Epidemiologia e Distribuição Espaço-Temporal da Raiva no Espírito Santo, entre os anos de 1994 e 2013. 2015. Vitória. Dissertação (Mestrado em Ciências da Saúde), Universidade Federal do Espírito Santo. 
Disponível

em: <http://repositorio.ufes.br/bitstream/10/5561/1/tese_8812_Disserta\%C3\%A7\%C3\%A 30\%20Karina\%20Marinho.pdf>. Acesso em 14/10/2019.

MIALHE, P. J.; MOSCHINI, L. E. Análise de fatores de receptividade e vulnerabilidade na elaboração de modelo de risco de ataques de morcegos hematófagos a bovinos no município de São Pedro - SP Archives of Veterinary Science, v.23, n.2, p.72-83, 2018 Disponível em: https://revistas.ufpr.br/veterinary/article/view/52298

MIALHE,P. J. Preferential prey selection by Desmodus rotundus (E. Geoffroy, 1810, Chiroptera, Phyllostomidae) feeding on domestic herbivores in the municipality of São Pedro - SP. Brazilian Journal of Biology, v.74, n.3, 2014. Disponível em: <https://doi.org/10.1590/bjb.2014.0086>. Acesso em 14/10/2019

MORAES, J.E.C.; ZANATA, A.F.; THOMÉ, C.M.; MOREIRA, D.B.; PRESOTTO, D.; DA COSTA, I.C.; BORGES, M. S.; RODRIGUES, R. C. A.; MARTINS, R.S. Raiva felina no município de Jaguariúna, Estado de São Paulo, em 2010. BEPA, Boletim Epidemiológico Paulista, v.8, n.96, p.04-10, 2011. Disponível em: $<$ http://periodicos.ses.sp.bvs.br/scielo.php?script=sci_arttext\&pid=S1806$42722011001600001 \& \operatorname{lng}=p t>$. Acesso em 14/10/2019.

MOURA, A.C.M. Reflexões metodológicas como subsídio para estudos ambientais baseados em análise multicritério. In: Simpósio Brasileiro de Sensoriamento Remoto, n. XII, 2007, Florianópolis. Anais do XII SBSR. Florianópolis, INPE, 2007, p. 2899 Disponível em: <http://marte.sid.inpe.br/col/dpi.inpe.br/sbsr\%4080/2006/11.13.14.41/doc/28992906.pdf>. Acesso em 14/10/2019.

MOUTINHO, B.; FERNANDO F.; DO NASCIMENTO, E.R.; PAIXÃO, R.L. Raiva no Estado do Rio de Janeiro, Brasil: análise das ações de vigilância e controle no âmbito municipal Ciência \& Saúde Coletiva, v. 20, n. 2, pp. 577-586, 2015. Disponível em: <https://www.scielo.br/scielo.php?script=sci_abstract\&pid=S1413$81232015000200577 \&$ Ing=en\&nrm=iso\&tlng=pt>. Acesso em 14/10/2019.

MUNIER, N. A strategy for using multicriteria analysis in decision-making. A guide for simple and complex environmental projects. ed. Springer, 2011. 298p. Disponível em: https://link.springer.com/book/10.1007/978-94-007-1512-7 Acesso em 14/10/2019.

NOGUEIRA, M.R.; LIMA, I.P.; MORATELLI, R.; TAVARES, V.C.; GREGORIN, R.; PERACCHI, A.L.; Checklist of Braziliam bats, with comments on original records. Check List., v.10, n.4, p.808-821, 2014. Disponível em: <https://biotaxa.org/cl/article/view/10.4.808/9731 >. Acesso em 14/10/2019.

NOWAK, R. M. Walker's Mammals of the World. v.1 6ed. Baltimore and London: The Johns Hopkins University Press, 1999, 836p.

OLIVEIRA, P.R; SILVA, D.A.R.; ROCHA, J.H.; DE MELO, S.M.A; BOMBONATO, N.G.; F.O.; CARNEIRO E SILVA, F. O. Levantamento, cadastramento e estimativa 
populacional das habitações de morcegos hematófagos, antes e após atividades de controle, no município de Araguari, MG. Arquivos do Instituto Biológico, São

Paulo, v.76, n.4, p.553-560, 2009. Disponível em: (http://www.biologico.agricultura.sp.gov.br/uploads/docs/arq/v76_4/oliveira1.pdf>. Acesso em 14/10/2019.

PINTO, J.L.C. Modelagem e Análise Geográfica Integrada das Variáveis Ambientais e Sócioeconômicas para o Mapeamento da Ocorrência de Morcegos em Belo Horizonte. 2015.Dissertação (Mestrado em Análise e Modelagem de Sistemas Ambientais), Instituto de Geociências, Universidade Federal de Minas Gerais. Disponível em: <https://repositorio.ufmg.br/handle/1843/IGCM-A33RA7 >. Acesso em 14/10/2019.

PISA, A.C.C. Efeito do controle de morcegos Desmodus rotundus na ocorrência de focos de raiva no estado do Espírito Santo. 2015. Pirassununga. Dissertação (Mestrado Medicina Veterinária Preventiva e Saúde Animal). Faculdade de Medicina Veterinária e Zootecnia - Departamento de Medicina Veterinária Preventiva e Saúde Animal, Universidade de São Paulo. Disponível em: <https://www.teses.usp.br/teses/disponiveis/10/10134/tde-25082015-102004/ptbr.php>. Acesso em 14/10/2019.

REIS, N.R.; PERACCHI, A.L.; BATISTA, C.B.; LIMA, I.P. História Natural dos Morcegos Brasileiros - Chave de Identificação de Espécies. Editora Technical Books, 2017.

SAATY, T.L. 1992. Multicriteria Decision Making: the analytical hierarchical process. RWS, Pittsburg. 125p.

SADASIVUNI, R.; O'HARA, C.G.; NOBREGA, R.A.A.; DUMAS, J. A transportation corridor case study for multi-criteria decision analysis. Proceedings of the American Society of Photogrammetry and Remote Sensing Annual Conference, Baltimore. $2009 . \quad$ Disponível em: https://pdfs.semanticscholar.org/e9bc/82dec18d43393e4c9bccc4afb8bb72f57419.pdf Acesso em 14/10/2019.

SANTOS, D.V. Avaliação de riscos: emprego da técnica pelo Serviço Veterinário Oficial e identificação de áreas de risco para a febre aftosa no Rio Grande do Sul. 2016. Tese (Doutorado em Ciências Veterinárias), Universidade Federal do Rio Grande do Sul. Disponível em: <https://www.lume.ufrgs.br/handle/10183/142448>. Acesso em 14/10/2019.

SODRÉ, M.M.; GAMA, A.R.; ALMEIDA, M.F. Updated list of bat species positive for rabies in Brazil. Revista do Instituto de Medicina Tropical de São Paulo, v.52, n.2, p.75-81, $2010 . \quad$ Disponível em: <http://www.scielo.br/scielo.php?script=sci_arttext\&pid=S0036-6652010000200003>. Acesso em 14/10/2019.

TOMAZ, L.A.G.; ZORTEA, M.; DE SOUZA, A.M; JAIME, V.S. Isolamento do vírus rábico no morcego Carollia perspicillata em Niquelândia, Goiás Chiroptera 
Neotropical, $\quad$ v.13, $\quad$ n.1, $2007 . \quad$ Disponível em: <https://repositorio.bc.ufg.br/bitstream/ri/14464/5/Artigo\%20\%20Leonardo\%20Aparecido\%20Guimar\%C3\%A3es\%20Tomaz\%20-\%202007.pdf>. Acesso em 14/10/2019. 